\title{
DE "LO CRUDO A LO COCIDO": VARIACIONES SOBRE EL CANIBALISMO EN PEDRO DE CIEZA
}

Jorge Chen Sham

\section{(c) ${ }_{\mathrm{EY}} \mathrm{NO} \mathrm{ND}_{\mathrm{ND}}$}

Doi: https://doi.org/10.15517/rfl.v44i2.34666

URL: https://revistas.ucr.ac.cr/index.php/filyling 



\title{
DE "LO CRUDO A LO COCIDO": VARIACIONES SOBRE EL CANIBALISMO EN PEDRO DE CIEZA
}

\author{
FROM "THE RAW AND THE COOKED": VARIATIONS ON \\ CANNIBALISM IN PEDRO DE CIEZA
}

Jorge Chen Sham

\begin{abstract}
RESUMEN
Claude Lévi-Strauss plantea en su seminal libro Lo crudo y lo cocido ( $1^{\text {a }}$. edición en francés de 1964) la dicotomía de lo crudo/ lo cocido para reafirmar el pasaje hacia el desarrollo cultural y el establecimiento de lo alimentario en realción con el fuego y la cocina y, con tal finalidad, parte de mitos indígenas latinomericanos en donde se establece la evolución de la ingesta de carne humana hacia la animal cocida. Pero, ¿qué sucede cuando la ingestión de la carne humana pasa por el proceso de cocción y se describe unos procedimientos de preparación de los alimentos que marcan el pasaje de lo crudo a lo cocido? Esto es lo que veremos en una de esas crónicas del periodo primitivo, la de Pedro de Cieza de León, Crónica del Perú, el señorío de los Incas (Sevilla, 1553). Palabras clave: Pedro de Cieza de León, Crónica del Perú, el señorío de los Incas, Claude LéviStrauss, canibalismo, crónicas primitivas.
\end{abstract}

\begin{abstract}
In his seminal book The Raw and the Cooked (1964) Claude Lévi-Strauss establishes the dichotomy between the raw and the cooked to affirm the passage towards cultural development and the establishment of alimentation in relation to fire and cooking. He sources his observations on Latin American indigenous mythologies which trace the evolution of human meat consumption to that of cooked animal meat. But what happens when the consumption of human meat goes through the process of cooking and gastronomic procedures are described which mark the passage from the raw to the cooked? This is what we will examine in one of those chronicles from the primitive period: Pedro de Cieza de León's Chronicle of Peru, the Rule of the Incas (Sevilla, 1553). Key words: Pedro de Cieza de León, Chronicle of Peru, the Rule of the Incas, Claude Lévi-Strauss, cannibilism, primitive chronicles.
\end{abstract}

Retomo el título del primer volumen de Mitológicas, la obra seminal del antropólogo francés Claude Lévi-Strauss, con el título de Lo crudo y lo cocido ( $1^{\text {a }}$ edición en francés de 1964). Partiendo de la experiencia etnográfica, recordemos, Lévi-Strauss desea mostrar la realización de unas estructuras funcionales en los mitos, cuyo pensamiento objetivado permite establecer equivalencias y analogías. El mito aparece, entonces, como la realización de unas

Dr. Jorge Chen Sham. Universidad de Costa Rica. Escuela de Filología y Lingüística. Costa Rica. Miembro correspondiente de la Academia Nicaragüense de la Lengua y la Academia Norteamericana de la Lengua Española. Correo electrónico: jorgechsh@yahoo.com

Recepción: 10- 12- 2017

Aceptación: 19- 02- 2018 
categorías de "recíproca inteligibilidad" (1986, p. 22), que el analista debe hacer aflorar para volverlo operacional y significativo. En esta medida, Lévi-Strauss pretende analizar lo que él denomina unas categorías empíricas, las cuales funcionan en tanto pares discretos, lo crudo/lo cocido, lo fresco/lo podrido, lo mojado/lo quemado (1986, p. 11).

El antropólogo francés observa cómo estas categorías son "constitutivas de la comida" (1987, p. 15), sobre todo lo crudo versus lo cocido. Para ello, revisa un relato de los indios Ofalé-Chavante, del sur del Matto Grosso brasileño y encuentra en el mito del jaguar portador del fuego y de la esposa del jaguar, una clave para explicar la relevancia del fuego y de la cocina. Lo resumo de la siguiente manera: el jaguar toma por esposa a una joven que está asombrada de la abundancia de carne producto de su caza; pasa un tiempo y se van a vivir con los humanos a los cuales alimenta con carne asada; el jaguar provee de carne a toda la comunidad; la joven empieza a cazar también y va tomando rasgos felinos; su abuela la mata por miedo a esta transformación zoomórfica; el jaguar termina por abandonar a los humanos y ruge buscando venganza de esta afrenta de los humanos. Después de analizarlo y compararlo con otros mitos del mismo tipo, como el de los Bororo, del valle alto del Río Paraguay, LéviStrauss llega a afirmar lo siguiente:

El jaguar y el hombre son términos polares cuya oposición está doblemente formulada en lenguaje ordinario: uno come lo crudo, otro lo cocido; y sobre todo el jaguar se come al hombre, pero el hombre no come jaguar. [...] Para todo lo que posee hoy el hombre (y que el jaguar no posee ya más) haya podido venirle del jaguar (que lo poseía en otro tiempo cuando el hombre carecía de ello), es preciso, pues, que aparezca entre ellos el medio de una relación: tal es el papel de la mujer (humana) del jaguar. (1986, p. 87)

Por posición actancial la mujer ocupa aquí la función de intermediario, la cual debe ser eliminada porque los humanos se muestran, primeramente, temerosos, mientras se ha consumado la transferencia del saber de abastecerse con carne (asada) que implica aquí un estadio técnico superior y de una alimentación mejorada: así el jaguar cumplía la misión de satisfacer necesidades; era eso lo que les ofrecía a los humanos según el mito ofalé-chavante. En este sentido, señala Lévi-Strauss una diferencia temática, cuando otros mitos bororos apuntaban al jaguar como el animal que procuraba la tea encendida a los humanos, para que los humanos le robaran no solo el secreto de las flechas y el arco sino también el del fuego reparador (1986, p. 72). Lévi-Strauss concluye, con acierto de síntesis en De la miel a las cenizas, que existe una relación de equivalencia entre los mitos sobre el origen de la cocción de los alimentos y los del origen de la carne; uno es el medio y el otro la materia de toda cocina, para que el pensamiento antropológico subraye el par, fuego-carne y el antropólogo exponga con rotundidad la simetría estructural:

A más de ofrecer construcciones simétricas, los dos grupos están también, por tanto, en relación dialéctica: tiene que
existir la carne para que el hombre pueda cocerla; esta carne, traída a cuento por los mitos de la forma privilegiada
de la carne de queixada, será cocida por primera vez gracias al fuego obtenido por el jaguar [...]. (1987, p. 17)

Así, la materia prima por excelencia de la cocina es la carne, mientras que la caza para conservarse debe someterse a este proceso que es el origen de la cocina, de manera que, por extensión, el fuego se hace tanto el portador como el fundamento del hogar doméstico, centrado sobre la actividad culinaria y de la transmisión y desarrollo de los bienes culturales, indica con gran pertinencia Lévi-Strauss (1987, p. 20). A lo anterior, habría que agregar que el fuego hace la carne apta y propia para el consumo humano desde un punto de vista etiológico al matar las bacterias y parar la prodredumbre, lo cual llevaría la base para establecer la siguiente clasificación: 


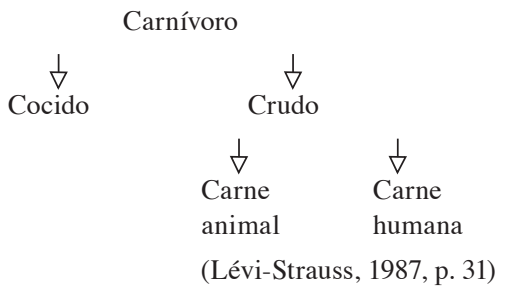

Según los mitos de los pueblos tenetehara y tembés de la costa nordeste del Brasil, al principio el ser humano comía carne cruda y el jaguar le enseñó a transformar sus alimentos por medio del fuego; aquel era un "comecrudo" (1987, p. 31) con estatuto de carnívoro y animal. Aquí introduce Lévi-Strauss, la categoría de devorador de carne humana, que según los mitos de los pueblos citados más arriba se castigaba, cuando el jaguar por despecho al ser humano se atrevió a hacerlo su alimento y fue transformado en tabaco para ser quemado después en castigo a su osadía. Nótese, en el esquema planteado por Lévi-Strauss, que él asocia la ingestión de carne humana a lo crudo, con lo cual este constituye un estadio anterior a la evolución social y que podía tanto ser censurado con un castigo como ser sometido al tabú social del desprecio y aislamiento, si se sigue practicando.

Si el paso de lo crudo a lo cocido parece ser el estadio previo hacia el desarrollo cultural, como hemos dicho más arriba, la diferencia de ingestión entre carne humana a la animal no solo está sometida también al tabú y a su rechazo social, sino que genera unos estereotipos devaluativos de lo salvaje y monstruoso, por ejemplo, siempre volviendo al caníbal. Recordemos que los términos canibalismo y caníbal remiten al contexto del descubrimiento del Nuevo Mundo y de las Islas del Caribe, en donde los indios caribes se comían a sus congéneres, es decir, eran comedores de sus semejantes. El canibalismo está estrechamente ligado a las "transgressions de la norme alimentaire" (Vandenberg, 2014, p. 21), para que su radio de acción sea, entonces, las costumbres y las normas alimentarias, las prácticas de alimentación y sus reglamentaciones culturales. En efecto, Vincent Vandenberg hace una distinción primera en cuanto a la noción de canibalismo y su percepción en la mente de los primeros viajeros en tierras americanas. Al caníbal se le achaca el hecho de comer carne humana o de comer hombres, no se refiere aquí a la acción de ingerir o destazar como lo hace un depredador en la naturaleza, porque se entra en el ámbito de una práctica, los alimentos y la comida, y su actividad posterior, la cocina, en el caso de que la carne humana se someta a su cocción. Vandenberg plantea con gran acierto este deslizamiento de la carne humana cruda a la percepción de normas de cocimiento y de aderezo propias: "il faut admettre que la simple application à l'humain de traitements, de gestes et de paroles assimilables à des pratiques de cuisines et d'alimentation peut être porteuse d'ambigüités qui la rapproche de l'antropophagie aux yeux -et dans les récits- de certains observateurs" (2014, p. 21).

Pero la cuestión se complica aún más históricamente, cuando el desarrollo de la cultura y el descubrimiento de América harán que la actividad del comer y la variedad de alimentos en el Renacimiento europeo permitan que el alimento en tanto trabajo/actividad humana adquiera una significación social preeminente: "L’aliment possède enfin une signification collective: la cuisson est signe de culture, la cuisine marque le groupe humain et en est marquée" (Pélicier, 1982, p. 15). Los libros de cocina (o de guisar, como se decía en buen castellano) adquieren su privilegio para que la participación en las comidas, el aderezo de los platos, el tipo de festines y las maneras de la mesa en tanto refinamiento cultural se impongan en la dicotomía 
moderación/cornucopia (Bierlaire, 1982, p. 149)1․ Pero, ¿qué sucede cuando la ingestión de la carne humana pasa por el proceso de cocción y se describen unos procedimientos de preparación de los alimentos que marcan el pasaje de lo crudo a lo cocido? Hay que prestar atención y cuidado a las observaciones y experiencias contadas por viajeros y cronistas, porque la noción de transgresión del alimento, del ser humano comido por su semejante, nos hace entrar en el terreno de lo decible/indecible, ya que

el canibalismo aparece asociado a la idea de alteridad, del otro bárbaro, primitivo y salvaje que consume carne
humana. [...] De mismo modo que los sacrificios humanos -o en otro plano el incesto-, el canibalismo planteó
problemas de orden moral para el hombre occidental, que vio en dichas prácticas manifestaciones de arcaísmo social
contrarias al progreso y a los valores sociales y familiares de su civilización. (Ponce, 2014, p. 173)

En efecto, en la visión eurocéntrica, la percepción y la narración de la antropofagia americana depende de esa manera de sustraerse y plantear los gestos, las palabras y los usos ligados a la alimentación normativa, porque comer carne humana es en principio una transgresión y un delito abominable. Su riesgo sería no saber ubicar lo que tanto viajeros y cronistas están abordando con fascinación pero también con temor.

Tomemos el ejemplo de Pedro de Cieza de León, quien escribió la Crónica del Perú, el señorío de los Incas (Sevilla, 1553); fue uno de esos conquistadores-soldados que estuvieron en el campo de batalla y, antes de partir hacia el Perú, estuvo en lo que se llamaba el Virreinato de Nueva Granada, más exactamente en la región del Valle de Cauca, a principios de 1539. Él se dirige a la villa de Ancerma (Umbra) y sus alrededores; describe en primer lugar a sus pobladores como "belicosos". Según Cieza, se caracterizan por sus armas y sus trofeos de guerra, al tiempo que toman rehenes, tal y como lo describe en el Capítulo XV: "Y a otros dan muertes temerosas, cortándoles algunos miembros, según su costumbre, a los cuales comen luego, poniendo las cabezas (como he dicho) en lo alto de las cañas" (Cieza de León, 2005, p. 48). Lo que más llama la atención de Cieza es la afirmación de "muertes temerosas", con los que califica las atrocidades y truculentas marcas de un espectáculo en el que se destazan a los rehenes, para que unas partes sean "comidas" en una suerte de comunión sacrificial, mientras que otras sean "puestas" como recordatorio del triunfo. Un párrafo después es aún más categórico: "Son grandes carniceros de comer carne humana" (Cieza de León, 2005, p. 49), en una suerte de redundancia, porque si "carnicero" se aplica al animal que come a otro y lo devora, el tabú del canibalismo se problematiza insistiendo en que se alimentan de "carne humana". También se justifica el hecho de que utilicen armas punzo-cortantes de gran calidad para combatir/defenderse y, luego para cortar/destazar. De manera que las armas se insertan dentro de una argumentación en donde el arte de guerrear y el de comer sus víctimas se prolonga en el destazamiento de trofeos/presas de la actividad bélica. Y para terminar, observemos que Cieza de León no emplea el término "canibalismo", mucho menos el de "antopofagia" más propio del siglo XX, sino que los denomina, "carniceros de comer carne humana".

Más adelante, en el Cap. XIX, cuando describe Cieza de León, su viaje de regreso desde la ciudad de Antiocha (así en el texto) a Cartago, pasa por la villa de Arma. Relata cómo eran estos indios, sus vistosos y adornados cuerpos con joyas de oro, sus alimentos y sus pueblos, para dedicarse prontamente a sus ritos y sacrificios. El conquistador español explica dentro de esa amalgama de propaganda fidei, que el demonio pervirtió la naturaleza de los indios y los hizo "pecar", de manera que la salvación y la redención de Dios actúa por las manos de los conquistadores. Todo ello sirve de justificación y de comentario previo a la descripción de los sacrificios de guerra que realizaban estos indios: 
De lo alto del tablado ataban los indios que tomaban en la guerra por los hombros, y dejándolos colgados, y a algunos de ellos sacaban los corazones y los ofrecían a sus dioses o al demonio, a honra de quien se hacían aquellos sacrificios, y luego sin tardar mucho comían los cuerpos de los que así mataban. (Cieza de León, 2005, p. 58)

La ingestión ceremonial se acompaña de la exhibición de los trofeos de guerra; el sacrificio ritual cobra todo su sentido, para que Cieza de León naturalmente no pueda extraer ninguna certitud que implique aquí una comprensión cultural. Es más, para los estudios postcoloniales, la antropofagia como tal se cuestiona hoy en día, como parte de esa fantasía eurocéntrica que solo pretende describir "una metáfora occidental de la diferencia cultural" (Münzel, 2010, p. 119), la cual causaba el horror y el miedo diferenciales. Pretenderlo de otra manera, o al menos ponerlo en duda, sería la tarea de quien interpreta estas crónicas. Seguirlo literalmente es hacer un anacronismo que también sería inapropiado por su óptica eurocéntrica/ cristiana, cuando más arriba él mismo explicaba que los comportamientos de los indios y sus actos se debían al demonio y a su desviación religiosa. Aquí Cieza de León describe desde el exterior, sin que muestre su aversión o su repulsa, eso es cierto, pero tampoco sin que pueda acercarse a lo que podría describir haciendo una indagación más completa. En los dos casos que se han descrito, la guerra es la causa de la antropofagia; él acota que los cuerpos han sido destazados con las armas y que se han comido. Lo que no sabemos es si el ritual (apenas se esboza) tiene un sentido colectivo y cultural, eso se escapa al ojo del conquistador, como tampoco si la carne humana se ha cocinado y se come cruda.

Más adelante, en este Cap. XIX, Cieza de León relata el caso que sucede con algunas mujeres embarazadas, después de insistir de que se trata de una sociedad matrilineal la que está describiendo en estas páginas:

\begin{abstract}
Son tan amigos de comer carne humana estos indios, que se ha visto haber tomado indias tan preñadas que querían parir, y con ser de sus mismos vecinos, arremeten a ellas, y con gran presteza abrirles el vientre con sus cuchillos de pedernal o de caña, sacar la criatura, y habiendo hecho gran fuego en un pedazo de olla tostarlo y comerlo luego, y acabar de matar a la madre y con las inmundicias comérsela con tan prisa que era cosa de espanto. (Cieza de León, 2005, p. 60)
\end{abstract}

En primer lugar, observemos cómo se acerca al evento utilizando un eufemismo, "amigos de comer carne humana", con lo que se comprueba esa idea de Vandenberg de que surge una cierta ambigüedad o malestar del conquistador español a la hora de abordar esta realidad, que él cataloga como "cosa de espanto". Tiene razón Mark Münzel en que no se trata actualmente de afirmar/negar la antropofagia de estos indígenas, pero allí están estos relatos de los viajeros y conquistadores que atestiguan haber convivido con esta realidad, aunque no sabemos cuánto de sus fantasmas y de sus mitos hayan influenciado sus crónicas (2010, p. 121). De igual manera, aquí Cieza de León describe un ritual, porque atestigua que era una costumbre comer los nonatos y a sus madres. Como arguye Münzel en esta óptica del relativismo cultural, "no es fácil distinguir claramente la interpretación de un ritual simbólico de la realidad imaginada a través de su representación ritual" (2010,p. 121), para que la ingestión de madres y nonatos no tenga un sentido dentro de una cosmovisión de renacimiento/muerte, en donde la antropofagia podría verse como una comunión con los muertos, en una suerte de prolongación del vínculo gracias al cordón umbilical, por ejemplo. Cieza de León señala, en este caso explícitamente, que hay una técnica de cocimiento de la carne humana, pero el asco y la reprobación se apoderan de él, cuando alude a que la cocinan "con las inmundicias". Todo indica que se trata de las tripas de la madre.

Más adelante, cuando en su periplo de Popayán hacia el Valle de Cali, Cieza de León relata las costumbres de los indios gorrones, que habitan en los alrededores de la ciudad de 
Cali, describe sus casas y, en relación con la costumbre de empalizar y adornar con miembros de cuerpos humanos tanto los umbrales de las puertas o sus exteriores, indica lo siguiente:

Junto a las puertas de sus casas por grandeza tienen de dentro de la portada muchos pies de los indios que han muerto, y muchas manos, sin lo cual de las tripas porque no se les pierda nada, las hinchen de carne, o de ceniza, unas a manera de morcilla, y otras de longanizas, de esto mucha cantidad. Las cabezas por consiguiente tienen puestas, y muchos cuartos enteros. (Cieza de León, 2005, p. 78)

Esta vez, Cieza de León describe una serie de técnicas culinarias y formas de preparación de las carnes; por ejemplo, las técnicas del secado y del ahumado de la carne para conservarla del ambiente húmedo y cálido, al tiempo que describe la forma de preparar las carnes en forma de "morcilla" y de "longanizas". Con arreglo a su tradición culinaria, el conquistador español se enfrenta a la carne humana; las tripas, vísceras y partes del cerdo, del cual como indica el refranero hispano "hasta sus suspiros se aprovechan", se subrayan para que no se desperdicie nada. Aquí Cieza de León compara las técnicas de la preparación del cerdo con los productos alimenticios de los indios gorrones. El asombro viene a continuación, cuando señala no tanto el tabú de la ingestión de la carne humana como la imposibilidad de comerla por la dureza y la sequedad de esta en una no tan evolucionada técnica de conservación:

Un negro de un Juan de Céspedes, cuando entramos con el licenciado Juan de Vadillo en estos pueblos, como viese estas tripas, creyendo ser longanizas, arremetió a descolgarlas para comerlas lo cual hiciera, si no estuvieran como estaban tan secas del humo y del tiempo en que había que estaban colgadas. (Cieza de León, 2005, p. 78)

Desde este punto de vista, para el gusto y el paladar del otro europeo, esta carne no es apta para el consumo y no se valora como un alimento. Cieza de León insiste en el fiasco que se llevó el negro, para que la extrañeza y lo exótico se expongan en el desfase entre las ganas de comer tales "longanizas" y, con este fin, se utiliza un verbo que indica prolijidad y movimiento para saciar el apetito ("arremetió a descolgarlas") frente al resultado y la decepción ("estaban tan secas del humo y del tiempo"). Eso sí, la avidez y las ganas de comer aquí se imponen, sin estar consciente del tabú de comer humana. Lo mismo les sucedió a los conquistadores españoles en sus primeras expediciones por el territorio antioqueño, lo relata Cieza en el Cap. XVI, cuando realizaban sus escarceos por la villa de Anserma y se quedaron sin vituallas; esto prepara el desenlace de su relato. En este momento de necesidad apremiante, la expedición comió sin darse cuenta carne humana:

\footnotetext{
Porque entiendan los trabajos que se pasan en los descubrimientos, los que esto leyeren, quiero contar lo que aconteció en este pueblo, al tiempo que entramos en él con el licenciado Juan de Vadillo, y es que como tenían alzados los mantenimientos en algunas partes no hallábamos maíz, ni otra cosa que comer, y carne había más de un año que no la comíamos, si no era de los caballos que se morían, o de algunos perros, ni aun sal no teníamos, tanta era la miseria que pasábamos. Y saliendo veinte y cinco o treinta soldados, fueron a ranchear o por decirlo más claro a robar lo que pudiesen hallar, y [...] hallaron una olla grande llena de carne cocida, y tanta hambre llevaban, que no miraron en más de comer [...], mas ya que estaban bien hartos, un Cristiano sacó de la olla una mano con sus dedos y uñas, sin lo cual vieron luego pedazos de pies de dos o tres cuartos de hombre que en ella estaban. Lo cual visto por los españoles que allí se hallaron, les pesó de haber comido aquella vianda dándoles grande asco de ver los dedos y manos, mas a la fin se pasó, y volvieron hartos al real, de donde primero habían salido muertos de hambre. (Cieza de León, 2005, pp. 51-52)
}

Analizado en otro lugar desde la excusatio propter infirmitatem que justifica las razones por las cuales se haya violado la prohibición de comer carne humana, al asociarla a esa concepción cristiano-estoica de padecer los "trabajos" (Chen, 2013, pp. 80-81), no solo se 
revela una secreto ante la necesidad biológica de saciar el hambre, sino que se expone una comprensión al retardar la escena porque los elementos se presentan paulatinamente y no en forma completa. Construida bajo la sorpresa que significa descubrir "una mano con sus dedos y uñas", comprender que se trata de un cuerpo humano desmembrado, con "pedazos de pies de dos o tres cuartos de hombre", conduce a la repulsa inicial del "Cristiano": por necesidad se ve comiendo carne humana y esto es concomitante a la sorpresa del lector que reúne todos los elementos de la escena. Entonces, caer en el engaño en el que el hambre y el olor condujeron a los soldados; es decir, ser arrastrados por lo que se desprendía de la olla, se justifica en el hambre saciada, tal y como se expone al final de la cita: "mas a la fin se pasó, y volvieron hartos al real, de donde primero habían salido muertos de hambre”. La clave está en la perífrasis verbal "volvieron hartos", en donde la satisfacción del comer es evidente. Pero llama la atención la neutralización que, en este contexto, hace Cieza de León, cuando presenta esa carne como "aquella vianda", lo cual conlleva no solo un tipo de cocción sino también una apreciación gustativa hacia esa consideración de "la viande en raison de ses pouvoirs reconstituants et de sa finalité virile" (Rivière, 1982, p. 207), para que el soldado en campaña militar sacie su hambre y recobre sus fuerzas. Todo este contexto permite que se perdone ese desliz del "cristiano", por oposición al indio, que come carne humana sin tener conciencia de la transgresión del tabú. Aquí el cronista no se refiere a carne cruda, sino a carne cocida en un contexto en el que el canibalismo se atenúa para que el horror y el asco no sean insalvables. Ahora bien, la carne cocida en "una olla grande", olorosa y apetitosa para el hambriento, desemboca en esa toma de conciencia de que las circunstancias indujeron a tal transgresión.

En conclusión, esos cuerpos desmembrados y comidos seguidamente bajo formas de cocimiento y de preparación de alimentos entre los indios de Colombia, no causan esa repulsión y horror virulentos que, en otras crónicas del siglo XVII, estarán relacionados con la idolatría de los indios americanos y su tendencia demoniaca (Coello de la Rosa, 2005, p. 56). Cieza de León describe esa costumbre de aparejar en tanto trofeos de guerra o de comer en una suerte de comunión simbólica a sus enemigos o contrarios, aunque se le escapa esa capacidad etnográfica y antropológica (y con ello no le pedimos hacer un anacronismo, obviamente) que significa proporcionar contorno y sentido a las prácticas humanas, sobre todo "a la vida colectiva de las comunidades humanas alejadas de nuestros modos de existencia" (Le Breton, 2002, p. 61), toda vez que el cuerpo humano se inserta en una continuidad, que Gutiérrez Estévez observa en muchos mitos americanos en esta aleación entre "[c]uerpos descuartizados, cenizas de una hoguera encendida con sus pedazos, avatares celestes de sus órganos, huesos molidos y amasados" (2010, p. 16).

Así, la ingestión de la carne de sus víctimas y su cocción entran en este juego simbólico de recordatorio del dinamismo universal, cuando los cuerpos desmembrados y comidos "son imágenes que impregnan los mitos amerindios y forman una espiral de muerte y vida que nos succiona y traslada a los tiempos fundacionales del mundo, cuando el universo se formó de fragmentos del cuerpo humano" (Gutiérrez Estévez, 2010, p. 16). Esto no tiene por qué saberlo ni podría comprenderlo Cieza de León en la primera mitad del siglo XVI; pero sí el lector de este siglo XXI, preocupado por otorgarle un contexto de referencia, o al menos de relativismo, a lo que lee cuando Cieza de León describe las "carnicerías" de estos indios de la actual Colombia. En los entresijos de este discurso del conquistador, sí que se nota una grieta o al menos se desliza un cierto de malestar cultural, cuando el canibalismo, eso de descuartizar o desmembrar los cuerpos humanos, no se realiza, tal y como lo harían los animales salvajes, 
comiéndose en forma cruda; sino que se someten a formas de cocimiento y de preparación, las cuales implican un estadio de avance técnico y, desde el punto de vista cultural, una forma de refinamiento que a partir de Renacimiento hace, de la preparación de los alimentos, una práctica de sociabilidad social.

\section{Nota}

1. Lo contrario sería el festin pantagruélico que desarrolla M. Bajtín; por la pertinencia de este artículo se realiza este deslinde aquí.

\section{Bibliografía}

Bierlaire, F. (1982). Erasme, la table et les manières de table. En J.C. Margolin y R. Sauzet (Eds.). Pratiques \& discours alimentaires à la Renaissance. (pp. 147-160). París: G.-P. Maisonneuve et Larose.

Chen Sham. J. (2013) Las inscripciones corporales del indio: canibalismo y desnudez en Pedro Cieza de León. Revista de Filología y Lingüística, 39 (1), 77-84.

Cieza de León, P. (2005). Crónica del Perú, el señorío de los Incas. Franklin Pearse (Ed.). Caracas: Fundación Biblioteca Ayacucho.

Coello de la Rosa, A. (2005). Más allá del Incario: Imperialismo e historia en José de Acosta, SJ (1540-1600). Colonial Latin American Review, 14 (1), 55-81.

Gutiérrez Estévez, M. (2010). Esos cuerpos, esas almas: Una introducción. En M. Gutiérrez y P. Pitarch (Eds.). Retóricas del cuerpo amerindio. (pp. 9-55). Madrid/ Frankfurt am Main: Iberoamericana/ Vervuert.

Gutiérrez Estévez, M. y P. Pitarch. (2010). Retóricas del cuerpo amerindio. Madrid/ Frankfurt am Main: Iberoamericana/ Vervuert.

Le Breton, D. (2002). La sociología del cuerpo. Buenos Aires: Nueva Visión.

Lévi-Strauss, C. (1986). Mitológicas 1. Lo crudo y lo cocido. México, D. F.: Fondo de Cultura Económica.

Lévi-Strauss, C. (1987). Mitológicas 2. De la miel a las cenizas. México, D. F.: Fondo de Cultura Económica.

Margolin, J.-C y R. Sauzet. (Eds.). (1982). Pratiques \& discours alimentaires à la Renaissance: Actes du colloque de Tours de mars 1979. París: G.-P. Maisonneuve et Larose.

Münzel, M. (2010). Antropofagia y sentimientos. Venganza y cariño en el cuerpo devorado. En M. Gutiérrez y P. Pitarch (Eds.). Retóricas del cuerpo amerindio. (pp. 117-152). Madrid/ Frankfurt am Main: Iberoamericana/ Vervuert.

Pélicier, Y. (1982). Les nourritures à la Renaissance: essai de typologie. En J.C. Margolin y R. Sauzet (Eds.). Pratiques \& discours alimentaires à la Renaissance. (pp. 15-20). París: G.-P. Maisonneuve et Larose.

Ponce, N. (2014). Canibalismo y literatura: "Mister Taylor" de Augusto Monterroso. Cahiers des Amériques-Figure de l'Encre, 4, 171-187. 
Rivière, D. (1982). Le thème alimentaire dans le discours proverbial de la Renaissance française. En J.C. Margolin y R. Sauzet (Eds.). Pratiques \& discours alimentaires à la Renaissance. (pp. 201-217). París: G.-P. Maisonneuve et Larose.

Vandenberg, V. (2014). De chair et de sang: Images et pratiques du cannibalisme de l'Antiquité au Moyen Âge. Rennes: Presses Universitaire. 
